\title{
Poetry and Pedagogy: Exploring the Opportunity for Epistemological and Affective Development within the Classroom
}

\author{
Jennifer Hennessy, Carmel Hinchion, Patricia Mannix McNamara \\ Department of Education and Professional Studies, University of Limerick, Ireland
}

\begin{abstract}
This paper provides a review of the priority afforded to the development of pupils' affective and epistemic development within the contemporary poetry class. The paper reports on the findings of a research project which explored the experience of teaching and learning within the post-primary Leaving Certificate programme in Ireland. The research includes interview and questionnaire data obtained over a three year period from 2007-2010 from 80 post-primary teachers of Leaving Certificate poetry and 200 post-primary Leaving Certificate pupils. The paper highlights the malign impact of summative assessment on teachers' pedagogical aspirations, identifying widespread professional dissonance amongst the cohort. Resultantly, empirical data highlights the reduced opportunity for epistemic and affective development within the poetry class and its impact on pupils' learning experiences. Recommendations for pedagogical redress focus on the necessity for enhanced contemplative, critical and subjective inquiry within the poetry classroom.
\end{abstract}

\section{Introduction}

The pressures entailed in meeting the increasingly diverse range of demands imposed on the contemporary teacher are significant [1]. Hargreaves, cautions that teachers' work is becoming increasingly intensified, with teachers expected to respond to greater pressures under "conditions that are at best stable and at worst deteriorating" [2]. Central to this concern for teachers is the task of negotiating tensions arising between the contrasting dominant ideologies of neo-conservatism and instrumentalism within contemporary curriculum policy and discourse [3]. Underlining the instrumentalist ideology is the philosophy of education for economic expansion. Consequently, of secondary concern within this value system is the holistic development of the individual. From this perspective education, the curriculum and even knowledge itself becomes a means to an end, not an end in themselves [3]. For neo-conservatives, the canon of English literature and traditional school subjects define the essence of the curriculum. Those opposing neo-conservative ideologies argue that it does not afford recognition to the social and historical nature of knowledge [4]. So closely aligned are neo-conservative and cultural heritage values that the weight of expectation for the poetry teacher to reflect such values in their pedagogy is significant, given the historical dominance of the cultural heritage model of English education [5]. Followers of the cultural heritage tradition widely endorsed the power of poetry as a means towards cultural elevation, emphasising the responsibility of schools to lead children to an appreciation of those works of literature that have been widely regarded as amongst the finest in the language [6].

"Good poetry does undoubtedly tend to form the soul and character; it tends to beget a love of beauty and truth in alliance together, it suggests, however indirectly, high and noble principles of action, and it inspires the emotion so helpful in making principles operative." [7]

While the more problematic elitist and exclusionary virtues enshrined within the cultural heritage model are now widely rejected, allegiance to some elements of the tradition remain within English education discourse [8]. In an attempt to mediate between these contrasting educational ideologies and provide students with a broad and wide-ranging poetry foundation it is asserted that the contemporary English teacher tends to "occupy the middle ground" [9], recognizing the importance of offering students the opportunity to experience the canonical texts and "literary greats", in addition to acknowledging the more pragmatic duties of English teaching. From an epistemological perspective, this stance would strongly suggest a position of multiplicity on the part of the teacher [10], where it is felt that students should be taught to believe that information is neither absolute nor externally controlled and where pupils are encouraged to have different perspectives on texts, in an environment where "everyone has a right to his own opinion" [11]. However, in an education system which has been increasingly directed toward economic instrumentality [4], as is evident within the Irish context [12], tensions arising from this mediated stance within the teaching of English are widely acknowledged with the "delegated gatekeepers of both linguistic and critical literacies, facing new questions about the purposes and priorities of their discipline" [13]. The impact of globalisation has resulted in instrumentalism and technical rationalism emerging as the dominant traditions of thought within contemporary schooling structures; 
The role and function of education are undergoing dramatic changes in response to these economic imperatives. The notion of a broad liberal education is struggling for its very survival in a context of instrumentalism and technocratic rationality where the catchwords are “vocationalism”, "skills formation”, "privatization” “commodification,” and "managerialism” [14].

Responding to economic demands, preformativity, rather than constantivity has come to characterise educational policy [15]. Target setting, testing and assessment have become synonymous with the process of learning [16] in what Eisner describes as the development of an technicised cognitive culture [17]. Within this cultural framework it is asserted that the conditions required for intuitive insight are quite different than the subsequent dispassionate, logical testing of it [18]. Consequently, subjects of affective and subjective orientation such as poetry are severely challenged to withstand the patterns of standardisation evident across the curriculum. In addition, given that instrumentalism is charged with the marginalisation of the aesthetic in education [19], the challenge of holding 'the middle ground' for many poetry teachers is proving increasingly difficult. Within this culture, epistemological dualism [10] within the poetry classroom becomes a pedagogical concern. Outlining the emergence of what she terms a 'damaging epistemological shift', Marshall [20] cautions;

"Something very odd is happening to school English. There has been a subtle and barely perceptible shift, whereby what was once the lifeblood of the subject is in danger of being drained from it, leaving it devoid of the spirit it once contained.”

\section{The necessity for an interconnected approach to poetry pedagogy}

Pepin [21] suggests teachers' beliefs and conceptions are manifested in their practices and can be traced back to, amongst other constructions, their epistemological positions. In addition Trigwell et al., [22] have shown that approaches to teaching are directly related to approaches to learning. The value systems espoused by teachers' through their pedagogies therefore afford the potential to significantly influence pupils' learning experiences. The importance then of providing an educational experience espouses a critical approach to learning and encourages pupils' to achieve a mature epistemological understanding cannot be underemphasised.

Kuhn et al., [23] assert that an orderly progression in levels of epistemological understanding can be observed and the attainment of mature epistemological understanding is based upon the synchronization of the subjective and objective dimensions of knowing. Acknowledging this, the importance of incorporating both the subjective and objective, the cognitive and affective and the emotional and intellectual concurrently within the poetry classroom becomes evident. Pike [24] too asserts that the relationship between the emotional and intellectual is something which cannot be ignored if teaching in the arts is to be truly aesthetic. Drawing on the writings of Iser and Eliot, who assert that the highest of all teaching is essentially aesthetic in character, Pike argues for an 'aesthetic approach' to the teaching of aesthetic subjects such as poetry where the development of personal growth supersedes the transmission of knowledge

\section{Context}

Post-primary education in Ireland generally begins at the age of twelve and continues for six years. A common programme which aims to build on the education received at primary school, termed the Junior Cycle, is followed by students for the first three years leading to the Junior Certificate examinations. This is followed by an optional year, entitled Transition Year which aims to advance the personal, social, educational and vocational development of pupils. Subsequently, the Senior Cycle, (more commonly referred to as the Leaving Certificate years) spans two years and concludes with a summative Leaving Certificate examination. This research focuses on poetry teachers and pupils working within the Senior Cycle or Leaving Certificate years.

The following section of this paper details initial findings from a longitudinal research study which began in 2007 and is currently being conducted on the teaching and learning of poetry at Leaving Certificate Level in Ireland. The purpose of this research is to conduct an exploration into the poetry teachers' and pupils' perspectives on a range of pedagogical topics and ideological values. Claims outlined previously in this paper which summarise contemporary research in this field are supported by the initial findings of this on-going research study.

\section{Methodology}

This research uses the combined theoretical framework of the positivist and interpretative educational research paradigms in doing so this study takes a 'pragmatic research approach' [25]. The study comprised two key phases completed by both Leaving Certificate teachers and pupils.

Phase one was quantitative in nature and consisted of the completion of a self-administered questionnaire. The key objective for this stage of the research was to obtain preliminary findings on a number of central research questions from a broad 
range of geographical and culturally diverse schools. This data served to highlight areas of interest and relevance for phase two. Statistical analysis was performed using PASW (Predictive Analytics Software) Statistics v.17, while open responses were categorised based on emergent themes. Each category was codified and entered into the PASW. When analysing the data, simple descriptive analysis was required and utilised to provide an account of the practices and espoused views of the teachers and pupils involved. The teacher questionnaire was sent via postal distribution to 50 post-primary schools throughout the Republic of Ireland, while the pupil questionnaire was disseminated in 8 schools by the researcher.

Phase two was qualitative in nature and consisted of detailed semi-structured interviews with $10 \%$ of both research cohorts in a gender stratified sample of phase one participants. The interviews were semistructured in nature to enable to collection of data pertaining to specific beliefs while also affording teachers and pupils the opportunity to discuss issues of particular relevance to them. The purpose of this phase was to conduct an in-depth inquiry into the issues emergent from phase one. Phase two data were analysed via thematic content analysis.

\section{Research findings}

The teacher questionnaire (phase one) elicited a $58 \%$ response rate from the schools contacted, resulting in the phase one participation of 80 postprimary teachers of English. 10\% of the phase one research cohort partook in phase two interviews ( $\mathrm{n}=$ 8 post-primary English teachers). Table 1 illustrates the gender distribution of the research cohort for both teacher research phases.

Table 1. Leaving Cert English teacher participants

\begin{tabular}{|c|c|c|c|c|c|c|c|c|}
\hline \multirow[b]{2}{*}{ Phase 1} & SSB $^{*}$ & $\%$ & SSG* & $\%$ & $\mathrm{M}^{*}$ & $\%$ & Total & $\%$ Total \\
\hline & & & & & & & & \\
\hline Male & 7 & $9 \%$ & 3 & $4 \%$ & 15 & $19 \%$ & 25 & $32 \%$ \\
\hline Female & 12 & $15 \%$ & 17 & $21 \%$ & 26 & $32 \%$ & 55 & $68 \%$ \\
\hline Total P1 & 19 & $24 \%$ & 20 & $25 \%$ & 41 & $51 \%$ & 80 & $100 \%$ \\
\hline \multicolumn{9}{|l|}{ Phase 2} \\
\hline Male & 1 & & 0 & & 1 & & 2 & $25 \%$ \\
\hline Female & 1 & & 2 & & 3 & & 6 & $75 \%$ \\
\hline Total P2 & 2 & & 2 & & 4 & & 8 & $100 \%$ \\
\hline \multicolumn{9}{|c|}{$\begin{array}{l}\text { *Single sex boys' school (SSB) *Single sex girls' school (SSG) } \\
\text { * Mixed school (M) }\end{array}$} \\
\hline
\end{tabular}

Two hundred Leaving Certificate pupils from 8 postprimary schools took part in phase one of the pupil research. Twenty four pupils were then chosen at random from these schools to participate in phase two of the research. Table 2 illustrates the gender distribution of the research cohort for both pupil research phases.
Table 2. Leaving Cert English pupil participants

\begin{tabular}{|c|c|c|c|c|c|c|c|c|}
\hline \multirow[b]{2}{*}{ Phase 1} & SSB & $\%$ & SSG & $\%$ & M & $\%$ & Total & \% Total \\
\hline & & & & & & & & \\
\hline Male & 20 & $10 \%$ & 0 & $0 \%$ & 57 & $29 \%$ & 77 & $39 \%$ \\
\hline Female & 0 & $0 \%$ & 57 & $28 \%$ & 66 & $33 \%$ & 123 & $61 \%$ \\
\hline Total P1 & 20 & & 57 & & 123 & & 200 & $100 \%$ \\
\hline \multicolumn{9}{|l|}{ Phase 2} \\
\hline Male & 6 & & 0 & & 6 & & 12 & $50 \%$ \\
\hline Female & 0 & & 6 & & 6 & & 12 & $50 \%$ \\
\hline Total P2 & 6 & & 6 & & 12 & & 24 & $100 \%$ \\
\hline \multicolumn{9}{|c|}{ *Single sex boys' school (SSB) *Single sex girls' school (SSG) } \\
\hline
\end{tabular}

While establishing English teachers' perceptions of their role within the poetry class research participants were not limited to the identification of a singular purpose or role. Sixty per cent of poetry teachers asserted their role as the development of aesthetic appreciation amongst their pupils; "My purpose is to help pupils appreciate poetry as an artistic, aesthetic medium which they can relate to.", "To open students to the pleasure of cracking open and appreciating a form which they may think is difficult.", "I want to encourage a passionate engagement with poetry amongst my pupils.", "To inspire a lifelong love of poetry amongst my pupils". In addition $42.5 \%$ of teachers felt their purpose as a Leaving Certificate poetry teacher was to explain poems to their class and to help pupils pass their Leaving Certificate exam; "to deal with and prepare pupils for the Leaving Certificate exam.", "to provide various notes and questions on selected poems.", "to help students understand themes, structure and imagery to prepare for the exam.", "to educate, to prepare for the Leaving Certificate". However, this technical focus was noted by teachers to have a subversive effect on the accomplishment of their primary espoused ambition of aesthetic appreciation. As outlined by one teacher in relation to this dichotomy of ambition, "When it comes down to it we're working within the confines of the exam". Teachers' primary aims of inculcating an aesthetic pedagogy into the classroom were relegated to an aspirational or secondary ambition rather than an objective as outlined by another participant who noted; "My purpose is to prepare pupils for the exam and hopefully give them some love of poetry along the way".

Poetry teachers were unlikely to ask pupils to illustrate poems through an alternate expressive art form with over half (59\%) of teachers rarely (26\%) or never (33\%) using this teaching strategy. Seventy five per cent of poetry teachers surveyed 'never' (33\%) or 'rarely' (42\%) use drama-in-education when teaching, yet drama-in-education provides a highly accessible medium through which the 
affective domain via personal and social development can be catered for [26]. The use of response journals has been advocated as instrumental in the affective development of pupils [27], however $66 \%$ of poetry teachers who partook in this research stated they do not use response journals in their class. Composition is noted within the syllabus as a "vital necessity" [28] for Leaving Certificate pupils. Within the poetry class, composition provides rich terrain for the affective development of pupils [29], yet this activity also appears underutilised within the Leaving Certificate context. Sixty seven per cent of poetry teachers in this study stated 'sometimes/ rarely' encouraging their pupils to write poetry and a further $17 \%$ of teachers asserting they 'never' ask pupils to write their own poetry.

The Leaving Certificate English Syllabus in Ireland asserts that students must "develop an awareness of their own responses, affective, imaginative, and intellectual, to aesthetic texts” [28] in order to foster an aesthetic pedagogy in the classroom. Congruent to achieving this ambition in the teaching of poetry is a focus on the subjective response of the pupil to a poem. To this end teachers were asked to list the most frequently occurring pedagogical activities in their poetry class. 'Teacher questioning and class response' emerged as the most frequently utilised pedagogical strategy in the classroom with $88 \%$ of teachers citing the frequent use of this approach in the teaching of poetry. 'Teacher clarification' of poetry emerged as the second most frequently cited pedagogical approach with $77 \%$ of teachers noting the regular occurrence of this method in their class. The teacher centred nature of the poetry classroom was too reflected in pupils' responses where $54 \%$ of pupils asserted never personally analysing poetry in class in advance of their teacher's 'poetry clarification'. In addition, difficulties in terms of pupil self-efficacy and encouraging a subjective pupil response encountered by teachers in the teaching of poetry were also reflected upon in phase two of the research. Teachers discussed at length how many of their pupils sought to establish the 'correct' meaning to a poem thereby continually undervaluing their subjective interpretation of texts. Pupils highlighted their sense of frustration with what they perceived as the ambiguous nature of poetry with $71 \%$ of pupils asserting the 'problem with poetry is that you can never be sure you are 'correct' in your understanding of a poem. Evident too was a sense of dependency on the part of both poetry teacher and pupil for prescripted responses to questions on poetry, with exam pressure and time constraints being cited as the main instigating factors in this trend. As noted by one interviewee; "An awful lot of students now want to be spoon fed with notes and you have this ridiculous situation then where pupils are learning off essays by heart for the leaving cert which is crazy. Where is the originality going to come in?" Indeed while confidence levels pertaining towards the study of poetry amongst pupils emerged as positive, with $58 \%$ of pupils asserting themselves as 'confident' in their understanding of poetry, the primary reason cited for this sense of self-confidence amongst respondents was ownership of 'good notes'. Support for the use of traditional resources was also evident in pupil responses with pupils' citing teacher notes (53\%), the poetry textbook (42\%), notes accessible on the internet (29\%) and books of poetry notes (24\%) as the four most effective class resources for enhancing their understanding.

\section{Discussion}

The data highlights a pattern of professional dissonance amongst teachers of poetry at Leaving Certificate Level in Ireland, who identified a feeling of discomfort arising from the conflict between professional values and expected or required job tasks [30]. While for many teachers in this research, altruistic and intrinsic motivations may have provided the grounds for becoming a teacher, such motivations were felt to be far removed from the realities of teaching within a context that endorses curriculum uniformity, test scores, competitive individualism, league tables and extrinsic rewards $[17,31]$. As is evident from the findings of this research, teachers are increasingly being required to set aside personal beliefs and values and live 'an existence of calculation' [32]. Working within a framework in which 'value' appears to replace 'values' [32] the tensions between teachers' sense of professional purpose and sense of performative purpose resonated clearly in this research. For the majority of teachers in this research altruistic ambition defined their role conceptualisation. Discussions focusing on the role of the poetry teacher without reference to contextual constraints or situational limitations invariably centred on conceptions of developing aesthetic appreciation, encouraging engagement and enjoyment, inspiring a love of poetry within pupils; "I want to open the minds of students to the potential of poetry to communicate on issues of significance", "I want to enrich my pupils' lives and help then to discover the escapism of poetry.", "I want to encourage and enthuse my pupils and make learning fun and enjoyable for them". However, teaching in the manner aspired to here, is fraught with both promise and peril [33]. The perennial constraints of instrumentalism posited by teachers in this research highlight the perils of altruistic ambition within the poetry classroom and gives credence to the long standing notion of the 'say/do' dichotomy of Irish life [34]. Teachers in this research were vocal in their criticism of the impact of summative examination on their pedagogical aspirations, 
relegating the 'ideal' to the 'aspirational' as "everything is influenced by the dreaded exam paper". Despite calls for the teaching of poetry to reflect a poem's overall aesthetic unity [35, 36], practice appears dominated by a deep-rooted standardised approach to poetry analysis in which the transmission of dualism, the lowest level of epistemic development, appears to be well situated.

The relegation of teachers' espoused values in the face of pressures of standardisation and performativity was seen from this research to significantly impact on the potential to develop pupils' affective, subjective and epistemic sensibilities. The relegation of the affective and subjective in the teaching of poetry in order to meet the requirements of summative assessment emerged as a key theme. While it is widely acknowledged that enthusiastic teaching predicated on the deployment of a wide range of teaching and learning strategies, holds the key to successfully engaging pupils' in poetry lessons [35], the predominance of a 'traditionalist' approach to teaching poetry was openly conceded by research participants, who felt that the nature of curriculum assessment failed to provide space for a more aesthetic approach to the teaching of poetry. The use of illustration of poetry, drama-in-education techniques and poetic composition, all holding the potential to enhance pupils' subjective understanding remain a negated feature of the Leaving Certificate poetry classroom. Additionally, the use of response journals to track subjective poetic reflection was also marginalised within the participating teachers' pedagogies. Cogniscent of the necessity for the coordination of the objective and subjective dimensions of knowing in the development of epistemological understanding [23], it is to be noted that the malign impact of negation of the affective and subjective within the Leaving Certificate poetry class is multifaceted.

Teachers' pedagogies as reported on in this research highlight the predominance of a dualistic approach to the teaching and learning of poetry resulting in students increasingly conceptualising reasoning and analysis as distinct from academic achievement. The predominance of this model of teaching is evident through the central role played by teacher questioning, teacher clarification, passive pupil assimilation and recited response within the poetry class structure as outlined by respondents. The widespread provision of notes from teacher to pupil as reported upon by pupils in this research evidences the pervasiveness of dualism within the Leaving Certificate poetry class. The provision of notes can be seen to scaffold the conceptualisation of knowledge as absolute and the promotion of correct or incorrect responses to poetry. Highlighting the detrimental impact of such conceptualisations, Paulsen and Feldman [37] note that students with the naïve belief that the structure of knowledge is simple are less likely to have an intrinsic goal orientation, to appreciate the value of learning tasks, to perceive an internal control over learning, and to feel efficacious about their capacity to learn. The experience of learning poetry at Leaving Certificate Level as reported upon by students in this research consolidates the notion of the pervasive and accepted influence of dualism within the poetry classroom. Over half of the pupils in this research reported never personally analysing a poem, rather waiting for the teacher to 'clarify' the 'meaning' of the poem for them, as time spent analysing from the pupil's perspective was seen as wasteful; "We don't want to waste time figuring out the meaning." Pupils reported frustration with the 'wasteful' ambiguous nature of poetry which prevented expedient access to the 'meaning' or 'solution' of the poem. Moreover, pupils' highlighted support for a teacher centred, notes and textbook based class in which meaning is transparent and clearly defined. Within this value system, pupils defined achievement and 'meaningfulness' as correlated with knowledge retention rather than understanding; "I don't want to lose time analysing that could be spent learning something meaningful".

\section{Conclusions: Finding a balance}

The research highlights the existence of an aesthetic vision for poetry pedagogy amongst postprimary English teachers which embraces the affective and subjective and encourages elevated levels of critical engagement. Emergent also from the research is the complexity of effecting pedagogical ambition in a world of instrumentalism and widespread professional dissonance. In 'Harlem', Langston Hughes poses the question: what happens to a dream deferred?

$$
\begin{gathered}
\text { What happens to a dream deferred? } \\
\text { Does it dry up? } \\
\text { like a raisin in the sun? } \\
\text { Or fester like a sore - } \\
\text { And then run? } \\
\text { Does it stink like rotten meat? } \\
\text { Or crust and sugar over - } \\
\text { like a syrupy sweet? } \\
\text { Maybe it just sags } \\
\text { like a heavy load. } \\
\text { Or does it explode? }
\end{gathered}
$$

Deliberating the likely outcomes for a deferred dream, Hughes refuses to engage with the possibility of the dream dispelling. Hope and the concept of persistence resonate quietly within the poem. This research identifies the significant challenges facing teachers of poetry. It highlights the need to support teachers in their attempts to foster enhanced potential for epistemological and affective development within 
the classroom. Addressing the malign impact of absolutism, it has been asserted that this conventional epistemology "hands us a dangerous counterfeit in truth's place, one that may pass for truth, but in fact is partial and impoverished [18]. Indeed Pike [24] cautions against the very real dangers inherent in the virtual obsession with explicitness in teaching, especially in disciplines, such as poetry which seek to nurture aesthetic experience. The importance of encouraging honest subjective engagement and multiple meanings therefore remains a central concern for the poetry class. It is asserted that "to counter the dominant view of knowledge as neutral and capable of 'speaking for itself,' knowledge must be approached as problematic in its social construction" [38]. In striving to develop enhanced epistemological engagement reasoned argument provides a most productive path to knowledge [23], therefore acknowledgement of the benefits of 'sustained uncertainty' and 'contemplative inquiry' within the poetry class is central to achieving this ambition [18].

Whelan [39] discusses the value of achieving balance when engaging with poetry and the arts, arguing that balance should be sought between 'filiation' (that to which we are born) and 'affiliation' (that to which we aspire) in order to truly understand, create and engage with works of art, such as poetry. Drawing on the work of Whelan, it can be asserted that effective engagement with poetry in the classroom must acknowledge both a poem's affective and analytical attributes. Stevens [40] too argues the necessity for the coordination of subjectivity and objectivity where both should be treated as mutually beneficial rather than mutually exclusive. This notion of balance resonates deftly in the poem 'Lightenings viii' where Heaney [41] compares the work of a crewman to that of a poet;

The annals say: when the monks of Clonmacnoise

Were all at prayers inside the oratory

A ship appeared above them in the air.

The anchor dragged along behind so deep It hooked itself into the altar rails

And then, as the big hull rocked to a standstill,

A crewman shinned and grappled down a rope

And struggled to release it. But in vain.

'This man can't bear our life here and will drown',

The abbot said, 'Unless we help him'. So

They did, the freed ship sailed and the man climbed back

Out of the marvellous as he had known it. - Seamus Heaney

This poem provides an exposition of the challenges facing a poet, challenges which resonate powerfully for the teacher of poetry also. It details the 'marvellous' of experiencing and creating poetry which is somewhat suspended above everyday experience but yet which does not lose itself in aesthetic qualities. Heaney himself commented on this poem:

"I was devoted to this poem because the crewman who appears is situated: between the ground of everyday experience and the arier realm of an imagined world. An essential thingwhether you're the poet or the crewman - is to be able to move resourcefully between these two realms, not get yourself bogged down in quotidian, yet not to lose your head in the fantastic.” [42]

The challenge for teachers of poetry in achieving enhanced affective and epistemic development while working in a context of standardisation and uniformity is great. "Poetry and its rewards can be elusive” [35], however the benefits to be gleaned in the redress of poetry pedagogy hold promise. In the words of Seamus Heaney:

"I can't think of a case where poems have changed the world, but what they do is they change people's understanding of what's going on in the world."

\section{References}

[1] Townsend, T. and R. Bates, Teacher education in a new millennium: Pressures and possibilities, in Handbook of Teacher Education: Globalisation, Standards and Professionalism in Times of Change, T. Townsend and R. Bates, Editors. 2007, Springer: Dordrecht. p. 3-22.

[2] Hargreaves, A., Realities of teaching, in International encyclopedia of teaching and teacher education L.W. Anderson, Editor. 1995, Pergamon: Oxford. p. 80-87.

[3] Moore, R. and M. Young, Knowledge and the curriculum in the sociology of education, in Education and Society: 25 years of the British journal of sociology of education, L. Barton, Editor. 2006, Routledge: New York. p. 242.

[4] Stronach, I. and H. Piper, "Can Liberal Education Make a Comeback? The Case of "Relational Touch" at Summerhill School". American Educational Research Journal, 2008. 45(1): p. 6.

[5] Scholes, R., The Rise and Fall of English. Reconstructing English as a Discipline. 1998, New Haven: Yale University Press.

[6] Goodwyn, A., "English teachers and the Cox models". English in Education, 1992. 26(3): p. 4-10.

[7] Arnold, M., Essays in Criticism. 1908, London: Macmillan.

[8] Locke, T., "Constructing English in New Zealand: A report on a decade of reform". L1-Educational Studies in Language and Literature, 2007. 7(2): p. 5-33. 
[9] Branson, J., The future of English, in Teaching English: a handbook for primary and secondary school teachers, A. Goodwyn and J. Branson, Editors. 2004, RoutledgeFlamer: New York. p. 209.

[10] West, E.J., "Perry's Legacy: Models of Epistemological Development". Journal of Adult Development, 2004. 11(2): p. 61-70.

[11] Perry, W.G., Forms of Intellectual and Ethical Development in the College Years. 1970, New York: Rinehart and Winston.

[12] Gleeson, J., Curriculum in Context: Partnership, Power and Praxis in Ireland. 2010, Oxford: Peter Lang [13] Colarusso, D.M., Teaching English in the Global Age: Cultural Conversations, in Department of Curriculum, Teaching and Learning. 2009, University of Toronto: Toronto.

[14] Smyth, J. and G. Shacklock, Re-making Teaching: Ideology, Policy and Practice. 1998, London: Routledge.

[15] Miller, T. and G. Yúdice, Cultural policy. 2002, London: Sage Publications Ltd.

[16] Jeffrey, B. and G. Troman, Developing a performative identity, in European Conference on Educational Research: Theory and Evidence in European Educational Research. 2009, Open University: Vienna.

[17] Eisner, E.W., "What Can Education Learn from the Arts about the Practice of Education?" International Journal of Education \& the Arts, 2004. 5(4): p. 1-12.

[18] Zajonc, A., "Cognitive-Affective Connections in Teaching and Learning: The Relationship between Love and Knowledge". Journal of Cognitive Affective Learning, 2006. 3(1): p. 1-9.

[19] Higgins, C., "Instrumentalism and the clichés of aesthetic education: a Deweyan corrective". Education and Culture, 2009. 24(1): p. 6-19.

[20] Marshall, B., "The write kind of knowledge in English". Critical Quarterly, 2003. 45(4): p. 113-125.

[21] Pepin, B., "Epistemologies, beliefs and conceptions of mathematics teaching and learning: The theory, and what is manifested in mathematics teachers' work in England, France and Germany." TNTEE Publications, 1999. 2(1): p. 127-146.

[22] Trigwell, K., M. Prosser, and F. Waterhouse, "Relations between teachers' approaches to teaching and students' approaches to learning". Higher Education, 1999. 37(1): p. 57-70.

[23] Kuhn, D., R. Cheney, and M. Weinstock, "The development of epistemological understanding". Cognitive Development, 2000. 15(3): p. 309-328.

[24] Pike, M.A., "Aesthetic Teaching". Journal of Aesthetic Teaching, 2004. 38(2): p. 20-37.
[25] Onwuegbuzie, A.J. and N.L. Leech, "On Becoming a Pragmatic Researcher: The Importance of Combining Quantitative and Qualitative Research Methodologies". International Journal of Social Research Methodology, 2005. 8(5): p. 375-387.

[26] Wright, P.R., "Drama Education and Development of Self: Myth or Reality?" Social Psychology of Education, 2006. 9(1): p. 43-65.

[27] National Council for Curriculum and Assessment (NCCA). Draft Guidelines for Teachers of English: Leaving Certificate English Syllabus. 2010 [cited 201020 March ; http://www.curriculumonline.ie/uploadedfiles/PDF/lc_engl ish_guide.pdf. (Accessed on 20 March )

[28] National Council for Curriculum and Assessment (NCCA). Leaving Certificate English Syllabus. 2010 [cited $2010 \quad 10 \quad$ June ]; http://curriculumonline.ie/uploadedfiles/PDF/lc_english_s y.pdf. (Accessed on 10 June )

[29] Kennelly, B., What Poetry Does, in Resource Materials for Teaching Language, T. Mullins, Editor. 1999, NCCA: Dublin.

[30] Taylor, M.F. and K.J. Bentley, "Professional dissonance: Colliding values and job tasks in mental health practice". Community mental health journal, 2005. 41(4): p. $469-480$.

[31] Flutter, J. and J. Rudduck, Consulting pupils: what's in it for schools? 2004, London: Routledge.

[32] Ball, S.J., "The teacher's soul and the terrors of performativity". Journal of Education Policy, 2003. 18(2): p. 215 - 228

[33] Liew, W.M., Lessons on Reform: A Story of Teaching as Lived Practice, in Teachers as Learners: Critical Discourse on Challenges and Opportunities, O. Kwo, Editor. 2010, Springer: New York. p. 245.

[34] Lynch, K., "Ideology, Interests and Irish Education: Ciarán Benson Talks to Tom Garvin, Kathleen Lynch and Billy Roche". The Crane Bag, 1985. 9(2): p. 12-24.

[35] Hanratty, B., "Opening the windows of wonder: a critical investigation into the teaching and learning of poetry at Key Stage Four in Northern Ireland". Irish Educational Studies, 2008. 27(2): p. 147-158.

[36] Meehan, P., Slitting the Songbird's Throat to see What Makes It Sing, in Resource Materials for Teaching Language. Leaving Certificate English Syllabus, T. Mullins, Editor. 1999, NCCA: Dublin.

[37] Paulsen, M.B. and K.A. Feldman, "Student motivation and epistemological beliefs". New Directions for Teaching and Learning, 1999. 1999(78): p. 17-25.

[38] Britzman, D.P., Practice makes practice: A critical study of learning to teach. 2003, New York: State University of New York Press. 
[39] Whelan, K., Between filiation and affiliation: the space of art. The Value of the Arts, ed. T.A. Council. 2008, Dublin: The Arts Council.

[40] Stevens, D., "Draw your own conclusions: Teaching Pre-twentieth century poetry in an arts context". English in Education, 2007. 41(3): p. 54 - 66.

[41] Heaney, S., Seeing Things. 1991, London: Faber \&Faber.

[42] De Groot, E., Seamus Heaney, in Ashford: Writers in residence, S. Clarke, Editor. 2007, Ashford Books: Ashford. 